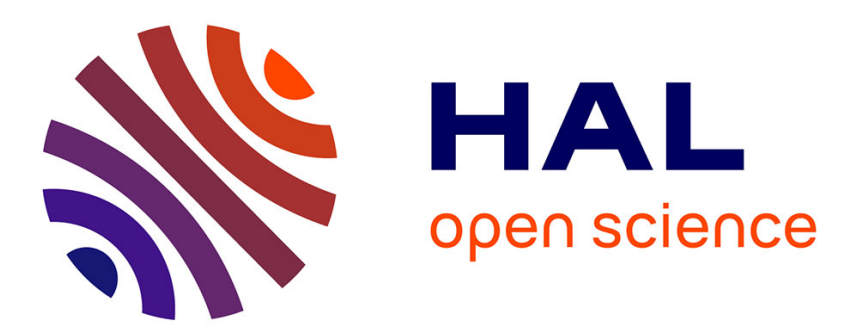

\title{
QUB/e - A novel transient experimental method for in situ measurements of the thermal performance of building fabrics
}

Johann Meulemans, Florent Alzetto, Farmer David, Christopher Gorse

\section{To cite this version:}

Johann Meulemans, Florent Alzetto, Farmer David, Christopher Gorse. QUB/e - A novel transient experimental method for in situ measurements of the thermal performance of building fabrics. International SEEDS Conference 2016: Sustainable Ecological Engineering Design for Society, Leeds Beckett University, Sep 2016, Leeds, United Kingdom. hal-01589176

\author{
HAL Id: hal-01589176 \\ https://hal.science/hal-01589176
}

Submitted on 18 Sep 2017

HAL is a multi-disciplinary open access archive for the deposit and dissemination of scientific research documents, whether they are published or not. The documents may come from teaching and research institutions in France or abroad, or from public or private research centers.
L'archive ouverte pluridisciplinaire HAL, est destinée au dépôt et à la diffusion de documents scientifiques de niveau recherche, publiés ou non, émanant des établissements d'enseignement et de recherche français ou étrangers, des laboratoires publics ou privés. 


\title{
QUB/E - A NOVEL TRANSIENT EXPERIMENTAL METHOD FOR IN SITU MEASUREMENTS OF THE THERMAL PERFORMANCE OF BUILDING FABRICS
}

\author{
Johann Meulemans ${ }^{1}$, Florent Alzetto ${ }^{1}$, David Farmer ${ }^{2}$ and Christopher Gorse ${ }^{2}$ \\ ${ }^{1}$ Saint-Gobain Recherche, 39 quai Lucien Lefranc B.P. 135, F-93303 Aubervilliers, France \\ ${ }^{2}$ Leeds Sustainability Institute, Leeds Beckett University, School of the Built Environment and Engineering, \\ Leeds, LS2 9EN, United Kingdom
}

Keywords: QUB/e, heat loss coefficient, U-value, in situ measurements.

\section{ABSTRACT}

This paper presents a novel transient experimental method developed in order to perform in situ measurements of the thermal performance of building fabrics: the QUB/e method. In one night, a QUB/e test yields the whole house heat loss coefficient (HLC) and the local in situ U-values. A comprehensive set of in situ measurements were carried out in a circa 1900 solid wall end-terrace house located in an environmental chamber to evaluate the thermal performance of the building fabric and to validate the QUB/e method. The accuracy of the QUB/e method was assessed against steady-state measurements before and after a deep retrofit, both the HLC and U-values were used in the comparison. The measurement of the $H L C$ using the QUB/e method for heating durations down to one hour yielded accurate results (i.e., the relative differences from the value estimated with the steady-state method were smaller than 10\%) provided the $\alpha$-criterion lay within the recommended range (i.e., between approximately 0.4 and 0.7). The U-values measured in situ with the QUB/e method were in good agreement with the steady-state (ISO 9869-1) values (i.e., the relative differences were within the uncertainty bound of the measurement methods). The QUB/e method was thus deemed validated by comparison with reference $U$-values measured in accordance with ISO 9869-1.

Meulemans, J., Alzetto, F., Farmer, D. and Gorse, C. (2016) QUB/e - A novel transient experimental method for in situ measurements of the thermal performance of building fabrics. In: Gorse, $C$. and Dastbaz, M. (eds), International SEEDS Conference 2016: Sustainable Ecological Engineering Design for Society, 14-15 September 2016, Leeds (UK). Leeds (UK): Leeds Beckett University. 


\section{INTRODUCTION}

The assessment of the energy performance of a building often relies on theoretical calculations. When the output of these calculations is compared to in situ measurements, the actual energy performance of a building often shows some discrepancy with the theoretical predictions (i.e., the so-called "performance gap", see Stafford et al. (2012), Johnston et al. (2015) and references therein). The mismatch between the "theoretical" and the real performances of a building can be due to material differences, ageing, thermal bridging, moisture, quality of construction (e.g., poor detailing and/or workmanship), and other factors.

In order to address the issues behind the "performance gap", the overall energy performance of a building is not enough, we need to know the local thermal performance of the building assembly, i.e. the contribution of each building element (walls, windows, roof and floor) to the whole heat loss coefficient (HLC) must be determined.

A novel dynamic experimental method, called QUB/e, which addresses most of the shortcomings of the available methods, was recently proposed (Meulemans and Alzetto, 2016). The accuracy of the QUB/e method was assessed on a lightweight building in a real climate by comparison with calculations (i.e., in accordance with standards ISO 6946 (International Organization for Standardization, 2007) and DIN EN 673 (German Institute for Standardization, 2011)) and quasistatic measurements (i.e., in accordance with standard ISO 9869-1 (International Organization for Standardization, 2014)). The agreement between calculated and measured U-values was good (i.e., the differences were within the uncertainty bound of the methods).

The QUB/e method is promising but its validation is incomplete, i.e. its accuracy (vs. quasi-static measurements) remains to be fully assessed. The main objectives of this research were two-fold:

1. Whole building thermal performance (heat loss coefficient, HLC): to improve the accuracy and reduce the duration of QUB tests (Mangematin et al., 2012; Pandraud and Fitton, 2013; Pandraud et al., 2013; Pandraud et al., 2014; Alzetto et al., 2014; Bouchié et al., 2014; Alzetto et al., 2016a; Alzetto et al., 2016b);

2. Local elements thermal performance (U-values): to validate the QUB/e method (Meulemans and Alzetto, 2016) vs. steady-state measurements (i.e., in accordance with ISO 9869-1).

A comprehensive set of in situ measurements were carried out in a circa 1900 solid wall endterrace house located in an environmental chamber to evaluate the thermal performance of the building fabric and to validate the QUB/e method. For both the whole house HLC and U-values, the accuracy of the QUB/e method was assessed by comparison with steady-state measurements before and after a full retrofit programme of the test house.

This paper is organised as follows. The materials and methods used in this study are described in Section 2. The results obtained from in situ measurements are presented and discussed in Section 3. Concluding remarks can be found in Section 4 . 


\section{MATERIALS AND METHOD}

\section{Salford Energy House}

The Salford Energy House is a full scale pre-1919 solid-wall Victorian end-terrace house constructed inside an environmentally controlled chamber at the University of Salford. The construction of the Salford Energy House Test Facility was achieved by using reclaimed materials and methods of the time. A guard house is also present so that the effects of a neighbouring property can be explored during experiments. For more details, the interested reader should refer to Ji et al. (2014), Farmer et al. (2015) and Alzetto et al. (2016b).

The baseline house was uninsulated and had single glazing. The full retrofit programme involved the application of mineral wool internal wall insulation (IWI) to the external walls of the test house. The IWI continued into the intermediate floor void and $400 \mathrm{~mm}$ along the party wall. The original windows were replaced by uPVC double glazed units (DGU). The loft was insulated with mineral wool quilt laid between and over the ceiling joists. PIR was installed between the joists of the suspended timber ground floor.

\section{Monitoring equipment}

Electrical heaters (i.e., fan heaters and heating carpets) were placed within the test house in order to provide a uniform heating source. Air circulation fans were used during the steady-state measurements in order to further homogenise the air temperature (Johnston et al., 2013; Farmer et al., 2015). Heat flux plates (Hukseflux HFP01), type $K$ thermocouples and PT100 resistance temperature detectors were used to monitor the heat flux densities on building elements and the air temperatures. A silicone paste was used to ensure a good thermal contact between the heat flux plates and the building elements. All sensors were connected to data loggers (Graphtek GL820 and dataTaker DT80). The data acquisition rate was set to one minute.

\section{Static measurements}

\section{Whole house heat loss measurements (Heat Loss Coefficient)}

A modified version of Leeds Beckett University's 2013 Whole House Heat Loss Test Method (Johnston et al., 2013) was used to obtain measurements of the test house HLC during each steadystate measurement period (Farmer et al., 2015; Alzetto et al., 2016b).

The test house and chamber were left undisturbed for a minimum period of 72 hours during which data were collected at intervals of one minute. To ensure continuous heat flow through the building envelope to the test chamber, a temperature differential $(\Delta T)$ between the internal and external environment of $15 \mathrm{~K}$ was selected for the steady-state measurements of whole house heat loss and in situ U-values. The test chamber HVAC equipment was set to maintain an air temperature of $5( \pm 0.5)^{\circ} \mathrm{C}$.

The internal environment of the test house and the guard house were heated electrically using fan heaters. A mean internal air temperature of $20{ }^{\circ} \mathrm{C}$ was maintained within the test house using thermostatic air temperature controls connected to each heater. A relatively homogeneous air 
temperature throughout the test house was facilitated by the use of air circulation fans, ensuring a similar temperature difference throughout the building envelope. Considerable care was taken to ensure that heat flux plates (HFPs) were not unduly influenced by excessive air movement by positioning fans in such a way that air was not blown directly on to the HFPs.

A steady-state was considered to be achieved if the heat flux density or the total power input differed by less than $\pm 5 \%$ from the value measured in the previous 24 -hour period.

The HLC was calculated using the following equation:

$$
H L C=\sum Q_{j} / \sum \Delta T_{j}
$$

where $Q_{j}$ and $\Delta T_{j}$ are, respectively, the electrical power input into the test house (in $W$ ) and the air temperature difference between the interior and exterior of the test house (in $K$ ) of the $j^{\text {th }}$ individual measurement. The calculation period was the last 24 hours of the steady-state measurement period.

$\mathrm{Q}_{\mathrm{j}}$ was obtained by measuring the electrical power input to the test house for the heaters, fans and logging equipment. $\Delta \mathrm{T}_{\mathrm{j}}$ was obtained by subtracting the arithmetic mean internal temperature of the house from the arithmetic mean chamber temperature.

The internal air temperature of the guard house was also maintained at $20^{\circ} \mathrm{C}$ throughout each 72 hour steady-state measurement period, this was to minimise inter-dwelling heat transfer across the party wall, as the party wall is considered a zero heat loss element in whole house heat loss calculations. HFPs were installed on the party wall to measure inter-dwelling heat transfer throughout each steady-state measurement period.

\section{In situ U-value measurements}

In situ U-value measurements were undertaken in accordance with ISO 9869-1 (International Organization for Standardization, 2014). In situ measurements of heat flux density, from which in situ U-values are derived, were taken at 49 locations on the thermal elements of the test house using heat flux plates (HFPs) as illustrated in Figure 1. Only measurements of heat flux density obtained from those locations that were considered not to be significantly influenced by thermal bridging at junctions with neighbouring thermal elements (typically at distances greater than 500 $\mathrm{mm}$ from the junction) were used in the calculation of the in situ U-values. One HFP was also placed at the centre pane of the window in the first bedroom, i.e. only the $U_{\mathrm{g}}$-value of this glazing could be derived from our measurements.

\section{Dynamic measurements}

The QUB/e method (Meulemans and Alzetto, 2016) was used to measure the whole house heat loss coefficient and local U-values. The QUB/e method is based on both the QUB and the heat flowmeter (HFM) (International Organization for Standardization, 2014) methods. The principle of the QUB method is based on a single resistance and capacity model (Mangematin et al., 2012; Pandraud and Fitton, 2013; Pandraud et al., 2013), and describes the temperature evolution as a single decaying exponential. By using two different constant powers in two different phases (respectively noted 1 and 2 ) the whole heat loss coefficient (HLC) of a building can be evaluated in one night (Pandraud et al., 2014; Alzetto et al., 2016a). 


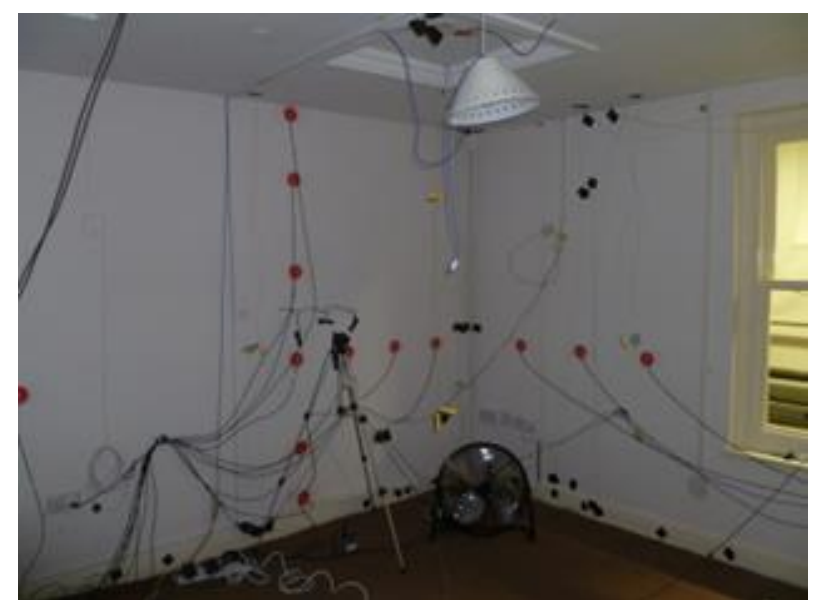

Figure 1 - Photograph of bedroom 1 in the test house showing HFPs (red discs) on the thermal elements

With the QUB/e method, heat flux densities and nearby air temperatures for each building element of interest are monitored during a QUB test. The QUB analysis procedure is then used to derive the U-values of each building element:

$$
U=\left(a_{2} q_{1}-a_{1} q_{2}\right) /\left(a_{2} \Delta T_{1}-a_{1} \Delta T_{2}\right)
$$

where $q_{i}, a_{i}$ and $\Delta T_{i}$ are, respectively, the mean heat flux density, the slope of the inside air temperature and the inside/outside air temperature difference at the 'end' of the $i^{\text {th }}$ phase (defined here as $t_{i}-\min \left(t_{i} / 2, \tau\right)$ where $t_{i}$ is the duration of the $i^{\text {th }}$ phase and $\tau=2 h$ ). The evolution of the heating power, the air temperatures and the heat flux passing through a building element during a QUB/e test is illustrated on Figure 2 .

The error on the estimated HLC with the QUB method depends on a dimensionless parameter called the $\alpha$-criterion (Pandraud et al., 2014; Alzetto et al., 2016a):

$$
\alpha=1-H L C_{r e f} \Delta T_{0} / P_{h}
$$

where $\mathrm{HLC}_{\mathrm{ref}}, \mathrm{P}_{\mathrm{h}}$ and $\Delta \mathrm{T}_{0}$ are a reference heat loss coefficient (in W. $\mathrm{K}^{-1}$ ), the heating power (in W) and the initial temperature difference (in K) between the internal and external environment (i.e., at the beginning of a QUB test), respectively. The HLC obtained from the steady-state measurements was used as a reference value here .HLC was studied for different heating duration: $0.5 \mathrm{~h}, 1 \mathrm{~h}$ and 4 h. The total duration of each test corresponds to twice these values (i.e., total time $=$ heating time + free cooling time).

While the influence of the $\alpha$-criterion on the estimation of the HLC with the QUB method was already reported in a previous project undertaken at the Energy House (Pandraud et al. 2014; Alzetto et al., 2016a), shorter durations were investigated in this project. 

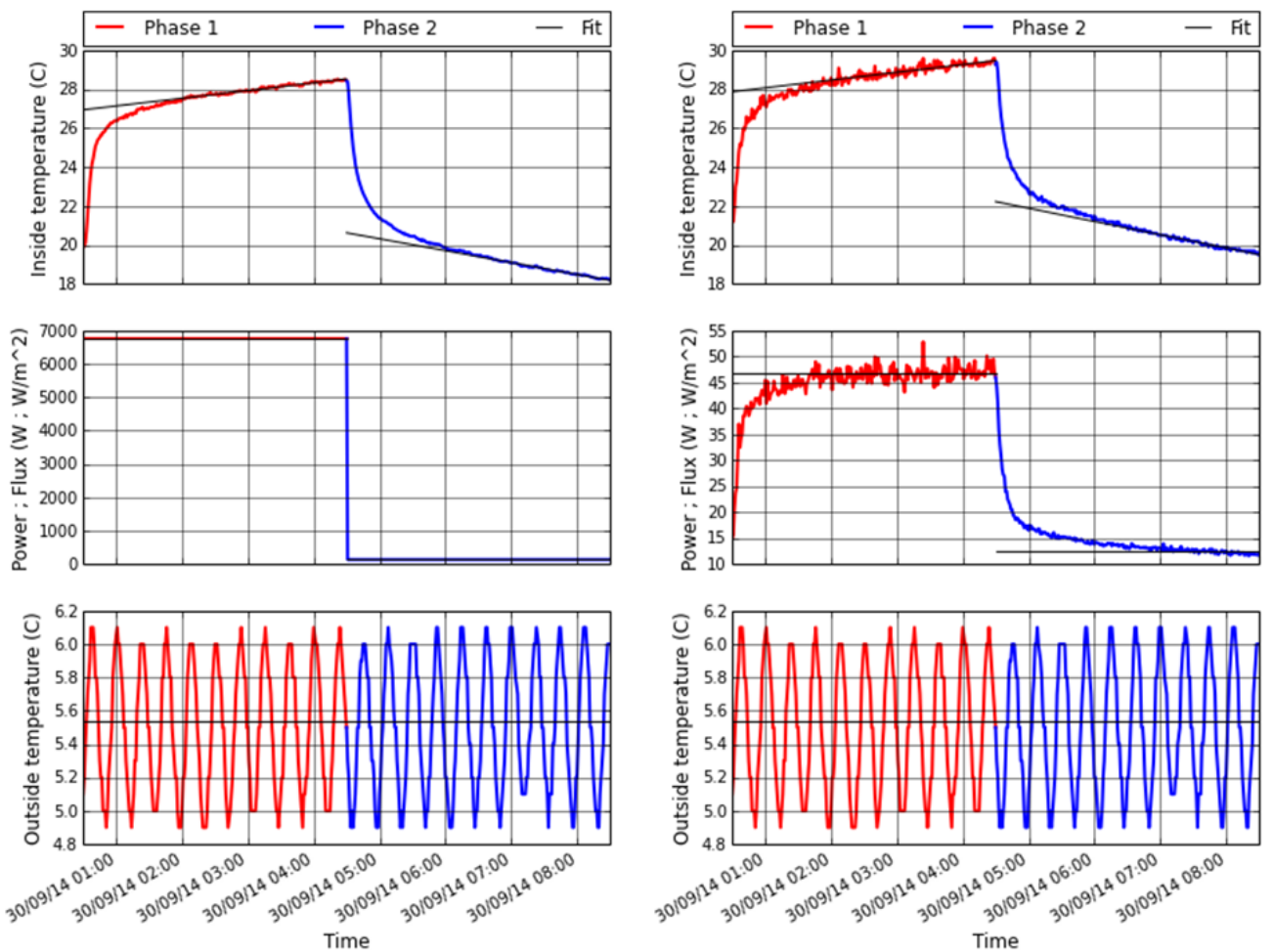

Figure 2 - Evolution of temperatures, heating power and heat flux density during a 4-hour QUB/e test - Baseline: whole house heat loss coefficient (left) and in situ U-value of an internal wall of bedroom 1 (right). The red, blue and black solid lines correspond to the heating phase, the free cooling phase and the linear regressions used to derive the quantities used in the QUB formula, respectively.

Since the indoor air temperature was not kept constant during the QUB/e test, there was a temperature difference across the party wall separating the test house and the guard house. Since the heat fluxes were monitored during the QUB/e tests, the heat losses at the party wall could be accounted for. The HLCs were thus corrected in order to report only heat losses to the exterior environment and have a sound comparison with the static measurements (in that case, there were no heat losses at the party wall since both houses were kept a constant indoor air temperature of $\left.20^{\circ} \mathrm{C}\right)$.

The corrected HLC was computed with the following equation:

$$
H L C_{\text {corr }}=H L C_{\text {raw }}-U_{\text {part }, e f f} \times A_{\text {part }}
$$

where $\mathrm{HLC}_{\text {corr }}, \mathrm{HLC}_{\text {raw, }} \mathrm{U}_{\text {part, eff }}$ and $\mathrm{A}_{\text {part }}$ are the corrected $\mathrm{HLC}$ (in W. $\mathrm{K}^{-1}$ ), the raw HLC (in W. $\mathrm{K}^{-1}$ ) obtained from the standard QUB analysis, the effective $U$-value of the party wall (in $W \cdot m^{-2} \cdot K^{-1}$ ) obtained from the QUB/e method and the area of the party wall (in $\mathrm{m}^{2}$ ), respectively.

In order to obtain reliable values, we repeated QUB/e measurements and derived representative values based on a statistical analysis. The mean values and standard deviations were reported for both HLCs and U-values. The U-values estimated in situ with the QUB/e method were compared with measured $U$-values using the static method described above. 


\section{RESULTS AND DISCUSSION}

\section{Whole building thermal performance}

Figure 3 shows the heat loss coefficients obtained with the QUB method for different heating durations. The HLCs are plotted against the $\alpha$-criterion calculated with a reference value taken from the steady-state measurements: $238.8( \pm 9.3)$ W.K $K^{-1}$ and $59.3( \pm 2.0)$ W.K $K^{-} 1$ for the baseline and retrofit stages, respectively. The experimental tests covered values of the $\alpha$-criterion between 0.2 and 0.8 .

For the baseline stage, comparison with static measurements suggested that the HLC derived from dynamic measurements could be slightly underestimated (around 10\%). However, the use of air circulation fans during the static measurements in order to homogenise the inside air temperature led to higher convective losses. For uninsulated (or poorly insulated) buildings (or building elements), the R-value is very sensitive to internal surfaces resistances (both internal and external). The discrepancy between the mean R-values derived from static and "long" dynamic measurements (i.e. 4-hour QUB tests) was approximately $0.07 \mathrm{~m}^{2} . \mathrm{K} . \mathrm{W}^{-1}$. This value corresponds to a difference of air velocity of a few meters per second in the vicinity of the building elements (e.g., see International Organization for Standardization (2007) and references therein) consistent with the use of air circulation fans. The 'true' HLC of the building should therefore lie between both values.

Another source of discrepancy arose from the effective heat losses at the party wall. The guard house was heated at a constant air temperature of $20{ }^{\circ} \mathrm{C}$ during the tests. For the static measurement performed at $20^{\circ} \mathrm{C}$, there were no heat losses through the party wall. Since the temperature was not kept constant during the dynamic tests, effective heat losses or gains at the party wall should be accounted for in the calculation of the HLC value derived from QUB test. An effective U-value was derived. However, there was a great dispersion in the obtained value and only 5 locations were monitored in our analysis.

The effective heat losses attributed to the party wall during the QUB/e tests were prone to uncertainty reflecting the non-uniformity of the party wall (e.g., chimney breast vs. cavity wall).

For "short" durations (i.e., $0.5 \mathrm{~h}$ and $1 \mathrm{~h}$ ), the HLC values estimated with the QUB method depended on the value of the $\alpha$-criterion (cf. Figure 3). The HLC was under-estimated (i.e., up to $50 \%$ ) for "low" values of the $\alpha$-criterion (i.e., smaller than 0.35 ). It should be noted that it was not possible to reach high values of the $\alpha$-criterion (i.e., greater than 0.7 ) at the baseline stage due to constraints on the available heating power. The 4-hour QUB tests did not exhibit any influence of the $\alpha$-criterion although the values tested remained around 0.5 (i.e., between 0.45 and 0.70 ).

For the retrofit stage, the observed over-estimation of the HLC (up to 70\%) for "short" durations (i.e., $0.5 \mathrm{~h}$ and $1 \mathrm{~h}$ ) was attributed to $\alpha$-criterion values larger than 0.7 (cf. Figure 3). The 4-hour QUB tests did not exhibit any influence of the $\alpha$-criterion although the values tested remained around 0.5 (i.e., between 0.45 and 0.65 ). Unlike the baseline stage, the static measurements were not impacted by the use of air circulation fans because the sensibility to surface thermal resistances was almost nil. 

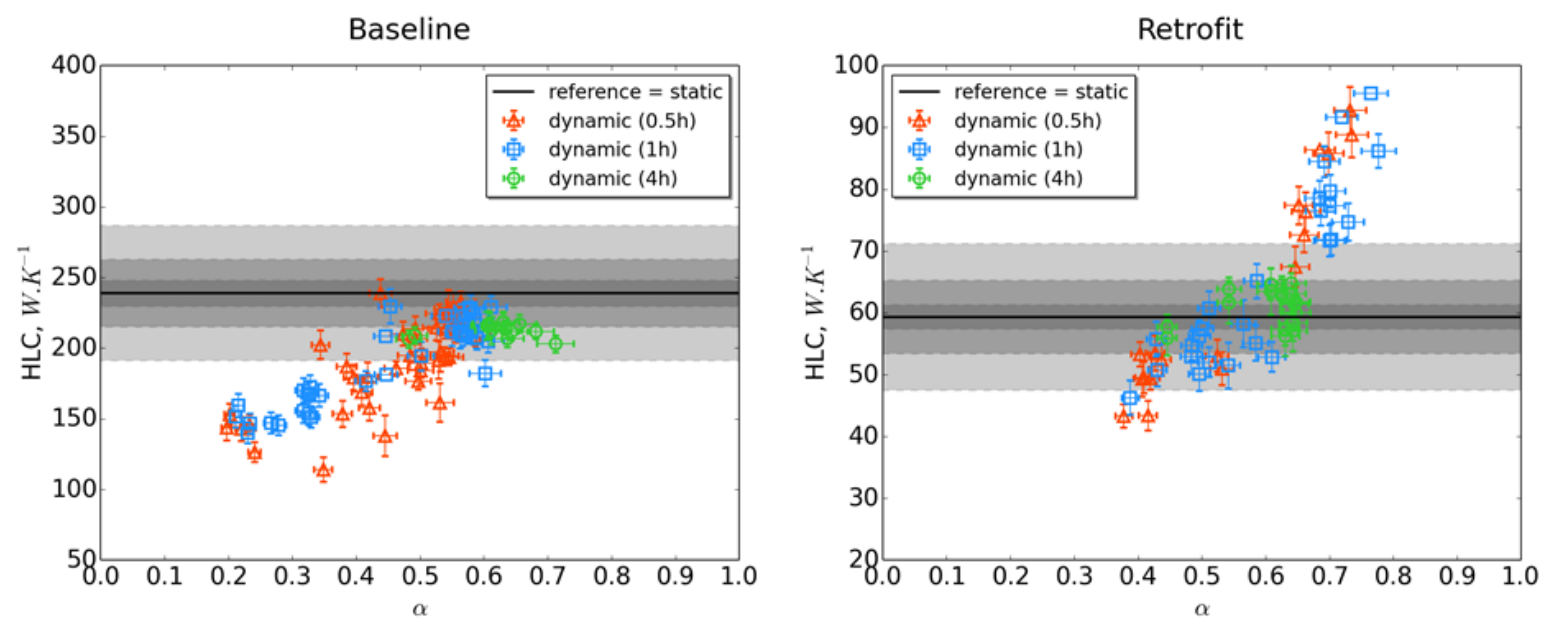

Figure 3 - Heat loss coefficient (HLC) vs. $\alpha$-criterion: baseline (left) and retrofit (right). Symbols: QUB tests, solid line = reference value. Grey-shaded area corresponds to $10 \%$ and $20 \%$ around the reference value, respectively. The reference value was taken from the steady-state measurements.

The $\alpha$-criterion can be viewed as a confidence index regarding the accuracy of each individual QUB measurement. If we only consider tests with values around 0.5 (i.e. $0.45-0.75$ and $0.4-0.6$ for the baseline and retrofit stages, respectively), the associated distribution of HLCs can be considered Gaussian. The obtained mean values were compared with the values derived from the static measurements in

Figure 4. The agreement between static and dynamic measurements was relatively good for both stages. 1-hour and 4-hour QUB tests yielded relative differences smaller than $10 \%$. For the (very) "short" heating durations (i.e., $0.5 \mathrm{~h}$ ), we obtained relative differences of $15 \%$.

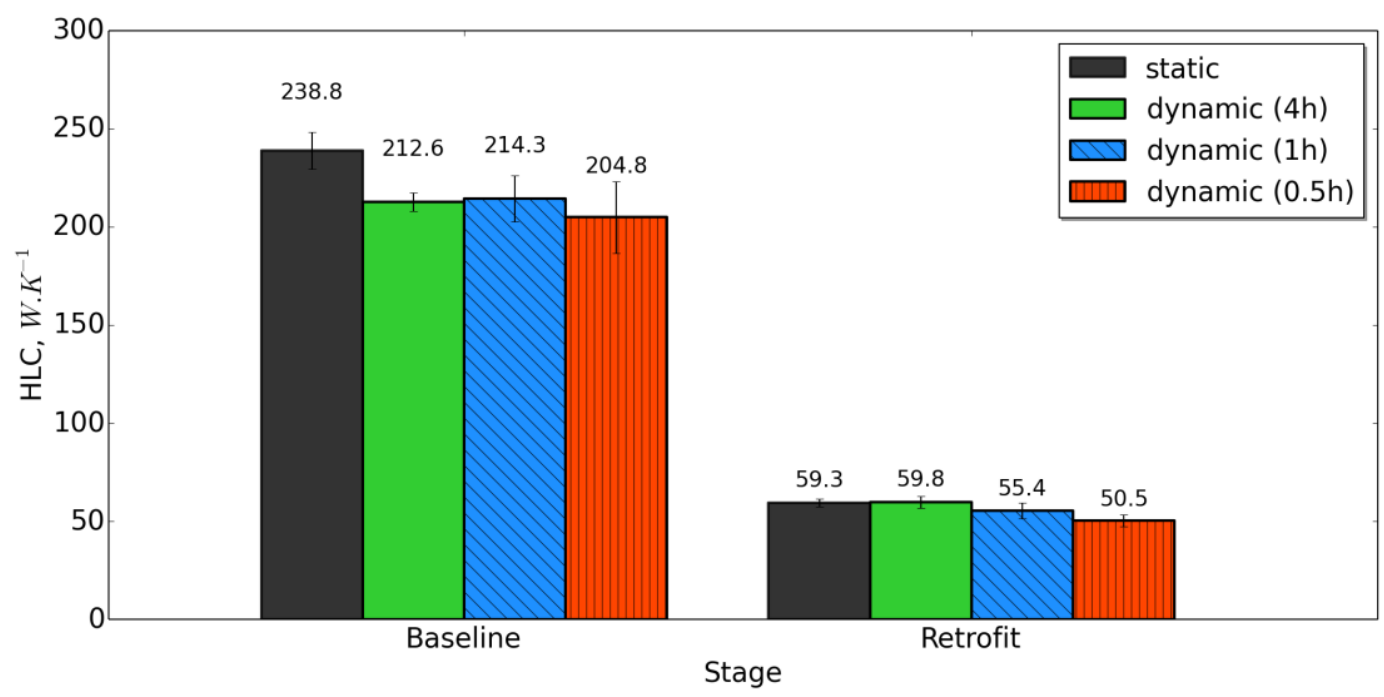

Figure 4 - Heat loss coefficient - dynamic vs. static measurements 
The associated uncertainty in the estimated HLC values with (very) "short" heating durations (i.e., $0.5 \mathrm{~h}$ ) could be largely due to dispersion in the estimated HLC for single QUB tests (cf. Figure 3). For a single (very) "short" QUB test (i.e., $0.5 \mathrm{~h}$ ), the estimated HLC might exhibit a relative difference up to $40 \%$ (vs. the reference value) even for an $\alpha$-criterion within the recommended range (i.e., between approximately 0.4 and 0.7 (Alzetto et al., 2016a)). This lack of robustness might be linked to the bias of the QUB method and should be further investigated.

For a single QUB test, the minimum heating duration needed to yield an accurate HLC value (i.e., relative difference with the value estimated with the steady-state method smaller than $10 \%$ ) was 1 $h$, provided great care was taken for the choice of the $\alpha$-criterion (i.e., values within the recommended range). This is consistent with previous findings (Pandraud et al., 2014; Alzetto et al., 2016a).

\section{In situ U-values}

The U-values measured in situ with the QUB/e and the steady-state (i.e., ISO 9869-1) methods are plotted against each other in Figure 5. Each symbol corresponds to the in situ U-value of each HFP placed on the different elements of the building (walls, glazings, roof and floor) for different heating durations (i.e., $0.5 \mathrm{~h}, 1 \mathrm{~h}$ or $4 \mathrm{~h}$ ). The mean values and the associated standard deviations computed over the different QUB/e tests are given.

Figure 5 shows that there was little (or no) influence of the heating duration on the estimated Uvalues with the QUB/e method. The main difference lay in the associated uncertainties (i.e., standard deviations): the shorter the test, the higher the uncertainty. The main source of uncertainty in the QUB/e method arose from the determination of the slopes at the end of each phase (heating and free cooling) since the external air temperature was kept constant at 5.5 ( \pm $0.5)^{\circ} \mathrm{C}$ during the tests. For (very) "short" durations (i.e., $0.5 \mathrm{~h}$ ), the number of data points available to determine the slopes was much less hence the greater uncertainty in the reported values.

The U-values measured in situ with the QUB/e method were in good agreement with the steadystate (ISO 9869-1) values (i.e., the relative differences were within the uncertainty bound of the measurement methods) except for the glazing and the roof at the baseline stage. The QUB/e method was thus deemed validated by comparison with reference $U$-values measured in accordance with ISO 9869-1.

The observed difference for the single glazing can be attributed to different internal surface thermal resistances during the tests. As previously mentioned, air circulation fans were used for the steady-state measurements and the internal surface thermal resistance was thus greater than the one during the QUB/e tests (no air circulation fans were used). For uninsulated (or "poorly" insulated) elements, the $U$-value is highly sensitive to the surface resistances (both external and internal). The observed difference for the roof at the baseline stage should be further investigated. 


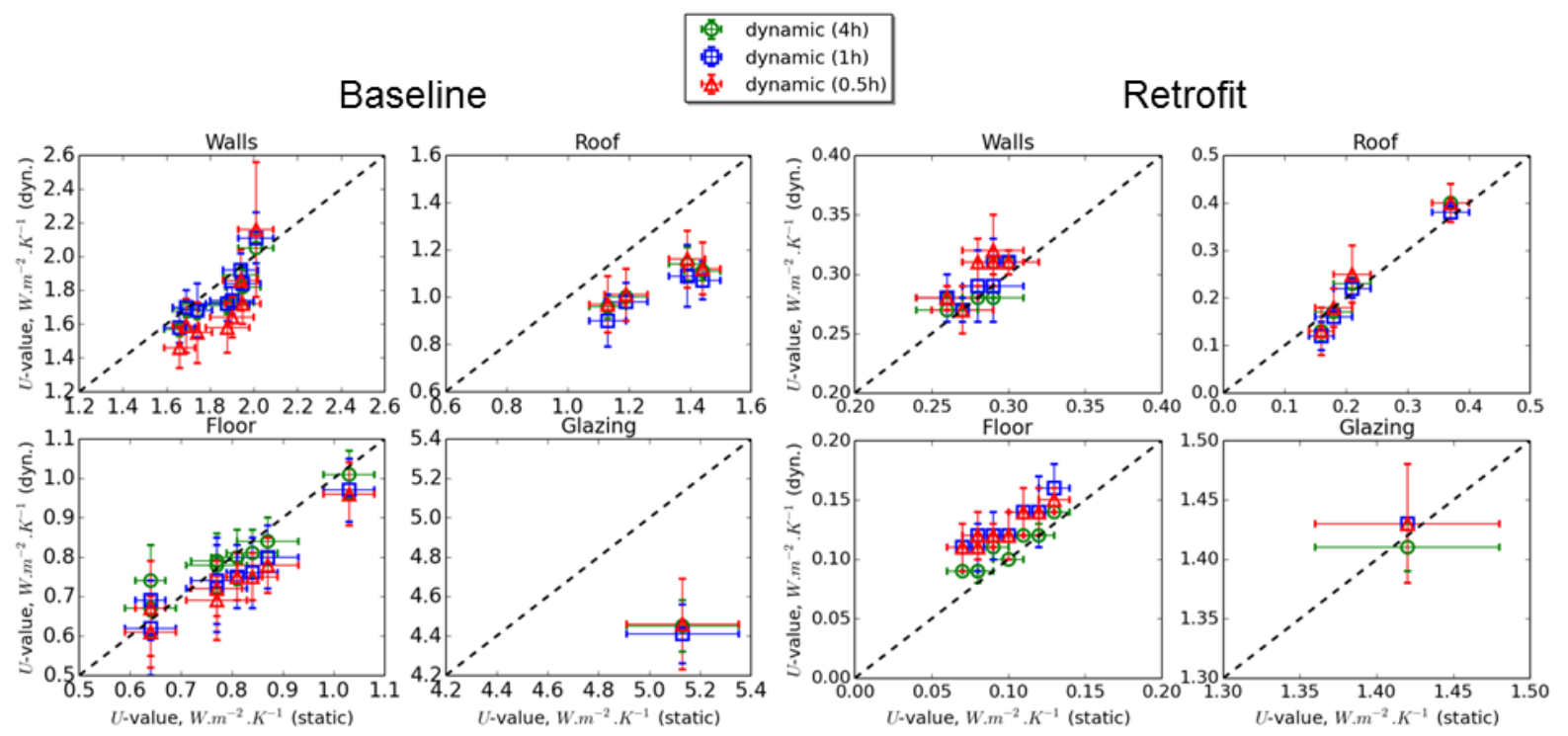

Figure 5 - Local U-values - dynamic vs. static measurements: baseline (left) and retrofit (right). For comparison, the $y=x$ reference curve is plotted for each case (dashed black lines).

\section{CONCLUSIONS}

A comprehensive set of in situ measurements were carried out in a circa 1900 solid wall endterrace house located in an environmental chamber to evaluate the thermal performance of the building fabric and to further improve/validate the QUB/e method. The following conclusions were drawn from the analysis carried out:

1 The measurement of the HLC with the QUB method for heating durations down to one hour yielded accurate results (i.e., the relative differences with the value estimated with the steady-state method were smaller than $10 \%)$ provided the $\alpha$ criterion lay within the recommended range (i.e., between approximately 0.4 and $0.7)$.

2 The measurement of the HLC with the QUB method for very "short" heating durations (i.e., down to half an hour) yielded highly dispersed HLC values (i.e., relative differences with the value estimated with the steady-state method up to $40 \%$ even for values of the $\alpha$-criterion within the recommended range).

3 The QUB/e method was deemed validated by comparison with reference U-values measured in accordance with ISO 9869-1 (i.e., the relative differences were within the uncertainty bound of the measurement methods).

It should be stressed out that these findings apply to measurements performed in a controlled exterior environment (i.e., constant exterior air temperature, no wind, no rain, no solar gains) at the Salford Energy House Test Facility. For measurements in the field, variability in the exterior environment as well as the likely unavailability of reference (measured) values makes it more challenging to reach a similar level of accuracy with the same confidence level. 


\section{ACKNOWLEDGEMENTS}

The funding of the project was provided by Saint-Gobain. The project management was under the responsibility of Luke Smith (National Energy Foundation). Richard Fitton and Mo Benjaber (University of Salford) provided the technical support for the operation of the Energy Hub during the project. The thermal upgrade of the test house was carried out by Jacob Eco Energy under the supervision of Saint-Gobain Habitat UK. The installation/removal of the sensors was carried out with the help of Olivier Samin (Saint-Gobain Recherche) and the Centre for the Built Environment (CeBE) of the Leeds Sustainability Institute of Leeds Beckett University (LBU).

\section{REFERENCES}

Alzetto, F., Gossard, D. and Pandraud, G. (2014) Mesure rapide de la perte thermique des bâtiments. In: Ecobat Sciences \& Techniques 2014 congress, 19-20 March 2014, Paris (France).

Alzetto, F., Pandraud, G. and Fitton, R. (2016a) The QUB Method: a Fast and Reliable Building Envelope Thermal Diagnosis. Energy and Buildings, submitted.

Alzetto, F., Farmer, D., Fitton, R., Hughes, T. and Swan, W. (2016b) Comparison of whole house heat loss test methods under controlled conditions in six distinct retrofit scenarios. Energy and Buildings, submitted.

Bouchié, R., Alzetto, F., Brun, A., Boisson, P. and Thébault, S. (2014) Short methodologies for in-situ assessment of the intrinsic thermal performance of the building envelope. In: Sustainable Places 2014, 1-3 October 2014, Nice (France).

Farmer, D., Gorse, C., Miles-Shenton, D., Brooke-Peat, M. and Cuttle, C. (2015) Off-the-shelf solutions to the retrofit challenge: thermal performance. In: Gorse, C. and Dastbaz, M. (eds), International SEEDS Conference 2015: Sustainable Ecological Engineering Design for Society, 1718 September 2015, Leeds (UK). Leeds (UK): Leeds Beckett University.

German Institute for Standardization (2011) DIN EN 673:2011 Glass in building - Determination of thermal transmittance (U-value) - Calculation method. Berlin (Germany): DIN.

International Organization for Standardization (2007) ISO 6946:2007 Building components and building elements - Thermal resistance and thermal transmittance. Calculation method. Geneva (Switzerland): ISO.

International Organization for Standardization (2014) ISO 9869-1:2014 Thermal insulation building elements - in-situ measurement of thermal resistance and thermal transmittance - Part 1: Heat flow meter method. Geneva (Switzerland): ISO.

Ji, Y., Fitton, R., Swan, W. and Webster, P. (2014) Assessing the overheating of the UK existing dwellings - A case study of replica Victorian end terrace house. Building and Environment, 77, pp. $1-11$. 
Johnston, D., Miles-Shenton, D., Farmer, D. and Wingfield, J. (2013) Whole House Heat Loss Test Method (Coheating). Leeds (UK): Leeds Metropolitan University.

Johnston, D., Miles-Shenton, D. and Farmer, D. (2015) Quantifying the domestic building fabric a 'performance gap'. Building Services Engineering Research and Technology, 36 (5), pp. 614-627.

Mangematin, E., Pandraud, G. and Roux, D. (2012) Quick measurements of energy efficiency of buildings. Comptes Rendus Physique, 13 (4), pp. 383-390.

Meulemans, J. and Alzetto, F. (2016) QUB/e - A novel dynamic experimental method for in situ measurements of the thermal transmission properties of building elements. Energy and Buildings, submitted.

Pandraud, G. and Fitton, R. (2013). QUB: Validation of a Rapid Energy Diagnosis Method for Buildings. In: IEA-EBC Annex 58, $4^{\text {th }}$ Expert meeting, 8-10 April 2013, Holzkirchen (Germany).

Pandraud, G., Mangematin, E., Roux, D. and Quentin, E. (2013) QUB: a new rapid building energy diagnosis method. In: Kabele, K., Urban, M., Suchý, K. and Lain, M. (eds), Proceedings of CLIMA 2013, the $11^{\text {th }}$ REHVA World Congress and the $8^{\text {th }}$ International Conference on IAQVEC, 13-19 June 2013, Prague (Czech Republic). Prague (Czech Republic): Society of Environmental Engineering (STP).

Pandraud, G., Gossard, D. and Alzetto, F. (2014) Experimental optimization of the QUB method. In: IEA-EBC Annex 58, $6^{\text {th }}$ Expert meeting, 14-16 April 2014, Ghent (Belgium).

Stafford, A., Bell, M. and Gorse, C. (2012) Building Confidence - A working paper. Report no: 008. Leeds (UK): The Centre for Low Carbon Futures. 